\title{
A AMAZÔNIA DE TAINÁ: UMA ANÁLISE SOBRE A REPRODUÇÃO DE CLICHÊS CULTURAIS NO CINEMA INFANTO- JUVENIL
}

\author{
RAFAEL DE FIGUEIREDO LOPES ${ }^{1}$
}

UFAM

\begin{abstract}
RESUMO: Este artigo analisa como a Amazônia é representada no filme "Tainá - Uma aventura na Amazônia” (2001). O objetivo é verificar se a obra citada está apoiada no reforço de estereótipos regionais e clichês culturais. Como embasamento teórico, optou-se por seguir o pensamento complexo de Edgar Morin, em diálogo com a ideia de "invenção da Amazônia", trabalhada por Neide Gondim, e com as noções trabalhadas em "A Sociedade do Espetáculo", por Guy Debord. O trabalho foi elaborado a partir de pesquisas bibliográficas e da observação do filme em questão. Conforme a análise realizada, foi possível constatar que a região é representada de forma exótica e seus personagens reforçam estereótipos cristalizados pelo senso comum. A bandeira da sustentabilidade e da preservação ambiental serve como um discurso superficial para justificar a proposta ecológica do filme.
\end{abstract}

PALAVRAS-CHAVE: cinema; Amazônia; clichês culturais.

ABSTRACT: This paper examines how the Amazon is portrayed in the movie "Taina - An Amazon Legend (2001)". The aim is to verify whether the movie is reinforcing regional stereotypes and cultural clichés. The theoretical framework includes Edgar Morin's "complex thought" theory, Neide Gondim's notion of "invention of the Amazon", and Guy Debord's ideas from "The Society of the Spectacle". The work is based on bibliographic research and observation of the movie in question. According to the analysis, the Amazon region is represented as exotic, and the movie characters reinforce stereotypes carried on by common sense. Sustainability and environmental protection are themes approached superficially, in order to justify the movie's proposal of discussing ecological issues.

KEYWORDS: cinema; Amazon; cultural clichés.

\section{Introdução}

\footnotetext{
${ }^{1}$ Rafael de Figueiredo Lopes é jornalista, ator e produtor audiovisual. Mestrando no Programa de PósGraduação em Ciências da Comunicação da Universidade Federal do Amazonas, bacharel em Comunicação Social pela Universidade Federal de Roraima. Pesquisador na linha de Linguagens, representações e estéticas comunicacionais, e voluntário em projetos sociais voltados à arte e cidadania. Bolsista da Capes. E-mail: rafaflopes@bol.com.br .
} 
Analisar como a região amazônica é retratada no cinema, contemplando o meio ambiente, o homem e a cultura, é um exercício muito amplo. Pode suscitar diferentes recortes, seja pelo viés documental, ficcional, experimental ou em animação, já que existe uma filmografia nacional e estrangeira de diferentes gêneros e com múltiplas abordagens sobre a região.

O cinema de ficção, por exemplo, tende a retratar a Amazônia de maneira exótica. Com raras exceções, segundo Soranz (2012), a região costuma ser restringida à exuberância de sua paisagem e aos aspectos folclóricos, enquanto as populações são inferiorizadas ou quase não têm destaque. Para o autor, o maniqueísmo - representado nos conflitos entre o homem "civilizado" e o "selvagem" - quase sempre fica evidente nas produções estrangeiras e também nacionais.

Paes Loureiro (2015), ao refletir sobre o discurso etnocêntrico propagada pelo cinema, considera que a imagem sobre a Amazônia se disseminou principalmente pelos filmes de ficção (aventura, ação, horror e fantasia) com temáticas sensacionalistas voltadas a representar aberrações (de tribos canibais até monstros pré-históricos) e o ambiente natural (do paraíso na terra, cheio de riquezas e farturas ao inferno verde com sua natureza hostil e perigosa).

A filmografia ${ }^{2}$ que reforça a espetacularização da cultura e da natureza amazônica transpassa diferentes períodos e estéticas. Podemos citar, por exemplo: O monstro da Lagoa Negra (JACK ARNOLD, 1954); Aguirre, a cólera dos deuses (WERNER HERZOG, 1972); Floresta das Esmeraldas (JOHN BOORMAN, 1985); Anaconda (LUIS LLOSA, 1997); Bem-vindo à Selva (PETER BERG, 2003); Um Lobisomem na Amazônia (IVAN CARDOSO, 2005) e a animação Rio 2 (CARLOS SALDANHA, 2014).

Obviamente, há inúmeros filmes que descontroem a imagem romantizada ou estereotipada da Amazônia e ressaltam com mais ênfase aspectos sociais, étnicos, políticos e culturais. É o caso, por exemplo, de: Iracema, uma transa amazônica (JORGE BODANZKY, 1976); A Festa da Menina Morta (MATHEUS NACHTERGAELE, 2009); Eu receberia

\footnotetext{
${ }^{2}$ Lista de produções cinematográficas com temática amazônica a partir do levantamento divulgado pelo Portal Amazônia. Disponível em: 〈http://portalamazonia.com/detalhe/noticia/confira-lista-de-producoescinematograficas-com-tematica-amazonica/?cHash=f5c863d1ef6bdc0b627ae97346f8776e > Acesso em 30 mar. 2016.
} 
as piores notícias dos seus lindos lábios (BETO BRANT, 2012); A Floresta de Jonathas (SÉRGIO ANDRADE, 2014) e Órfãos do Eldorado (GUILHERME COELHO, 2015). Sem contar inúmeros documentários que abordam diferentes perspectivas dessa "região-continente", mas que neste trabalho não serão citados pelo fato de estarmos concentrados no gênero ficção.

Diante desse panorama, para a possibilidade de uma análise prática, elegemos como foco o filme Tainá - Uma aventura na Amazônia (TÂNIA LAMARCA, 2001), que é o primeiro longa-metragem da trilogia composta por Tainá - A Aventura Continua (MAURO LIMA, 2004) e Tainá - $A$ Origem (ROSANE SVARTMAN, 2013), que são ficções do gênero ação/aventura direcionadas ao público infanto-juvenil.

Esse recorte [ficção-ação $\mathrm{x}$ público-alvo] determinou nossa escolha, partindo da ideia de que na infância e adolescência as descobertas marcam a formação de conceitos, preconceitos e parâmetros socioculturais. Portanto, a reflexão sobre uma obra que levanta a bandeira da valorização cultural de uma das etnias formadoras do povo brasileiro e da preservação do meio ambiente se torna pertinente quando pensamos em estereótipos e preconceito social. Afinal, será que Tainá apresenta (ou representa) - audiovisualmente consonância com a "realidade" vivida pelas comunidades indígenas da Amazônia ou apenas reproduz o que é "idealizado" sobre essa região e seus povos?

Além da observação e análise do filme em questão, o texto é baseado em levantamento bibliográfico de autores de diferentes áreas, no intuito de articular uma trama conceitual com ideias do "pensamento complexo", trazendo Edgar Morin; em conexão com aspectos sobre a "invenção da Amazônia", trabalhados por Neide Gondim; com as noções veiculadas em $A$ Sociedade do Espetáculo, por Guy Debord; e, ainda, considerações sobre gêneros cinematográficos e indústria do entretenimento.

Inicialmente, apresentaremos noções sobre as origens da construção do imaginário relacionado à Amazônia e como este se disseminou até os dias de hoje. Depois, contextualizaremos aspectos da história do cinema na região e refletiremos sobre a força dos gêneros ação/aventura. Por fim, analisaremos Tainá - Uma aventura na 
Amazônia, a fim de verificar se o tom fantasioso de sua narrativa (no sentido do exótico, elaborado por quem vê de fora) tem compromisso com a cultura amazônica ou seria uma estratégia para alimentar a dinâmica da indústria cultural.

\section{Amazônia: origens de um imaginário}

Como qualquer explorador, chegamos com imagens preconcebidas e com os mitos produzidos sobre ela, como o do território verde com populações indígenas, do paraíso, do pulmão do mundo, entre tantos outros. Como dizíamos, uma consideração ampliada do cultural pode vir a incorporar uma variedade de elementos, mas nossa inquietude se orienta especialmente para o modo como foram construídos, e ainda se constroem, no discurso, os imaginários sobre esta área (PIZARRO 2012, p. 29).

O caráter exótico atribuído ao imaginário sobre a Amazônia começou no século XVI, segundo Gondim (2007). A autora diz que "a Amazônia é uma invenção" a partir de relatos de viagens escritos pelos colonizadores, missionários, naturalistas e artistas. Essas viagens acenderam o imaginário dos europeus que sonhavam com o "paraíso e a fonte da eterna juventude".

A primeira grande expedição à região foi realizada entre 1540 e 1542, comandada pelo espanhol Francisco de Orellana (primeiro explorador a percorrer o curso do Rio Amazonas, do Atlântico aos Andes). As impressões dessa viagem são os primeiros registros sobre a Floresta Amazônica e a diversidade de ambientes e culturas encontradas. Foram escritos pelo frei Gaspar de Carvajal ${ }^{3}$.

Segundo os relatos, o grupo se confrontou com uma "tribo" (Icamiabas) na qual as mulheres demonstravam habilidades de

\footnotetext{
${ }^{3} \mathrm{O}$ texto da primeira viagem de navegação pelo Amazonas foi preservado através de duas cópias: uma conservada na Biblioteca da Real Academia de História e outra na Biblioteca Nacional de Madrid. A partir daí, entre os séculos XVI e XVIII, um importante conjunto de relatos sobre a Amazônia foi produzido por diversos sujeitos, fossem eles aventureiros, funcionários das coroas ibéricas ou missionários. Neles, assim como em Carvajal, podemos encontrar dados que destoam da noção corrente por muito tempo de que a floresta tropical fosse pouco adequada para a sobrevivência humana e carente de recursos que viabilizassem a concentração e o desenvolvimento populacional. Disponível em: http://anpuh.org/anais/wp-content/uploads/mp/pdf/ANPUH.S24.0758.pdf . Acesso em: 10 mai. 2015.
} 
guerreiras ao dispararem flechas e zarabatanas para defender seu território. Devido a essa postura destemida, os exploradores relacionaram as índias da "tribo" com as guerreiras Amazonas da mitologia grega, que na época ainda povoava a imaginação europeia, forjando no novo mundo um mito clássico. A partir daí, o lugar passou a ser conhecido como "o rio das amazonas".

A expedição de Orellana está relacionada com o fortalecimento do mito do Eldorado entre os exploradores, a suposta cidade com construções de ouro perdida no meio da floresta. Em espanhol, el dorado remete ao "homem dourado", numa possível referência ao soberano de uma "tribo", na atual Colômbia, que cobria o corpo com um pó dourado em reverência às divindades. A busca por esse lugar, que jamais foi encontrado, teria sido a motivação dessa e outras expedições que almejavam achar tesouros perdidos.

Esses e outros mitos passaram a estimular a criatividade de escritores. Alguns, sem jamais terem visitado a região, criaram romances cheios de aventura e mistérios. Além da literatura, a Amazônia foi retratada por meio de desenhos, gravuras, pinturas e pela fotografia, conforme Pinto (2006). Segundo o autor, pelo poder dos discurso e das imagens, como uma "viagem das ideias", as artes reforçaram ainda mais o sentido "exótico", que ganhou movimento e ainda mais reverberação com o cinema.

Cunha (1999) diz que o imaginário sobre a Amazônia e o índio nas produções audiovisuais, na maioria dos casos, não têm como referência o real ou o documental, mas o modelo construído pela literatura romântica, marcadamente idealizado, como atestam os inúmeros "guaranis", "ubirajaras" e "iracemas".

Gonçalves (2010, p. 21) chega a afirmar que "as imagens construídas pelo estrangeiro ou mesmo o brasileiro não egresso das populações periféricas da Amazônia estão permeadas por concepções alienígenas". Segundo o autor, essa visão se preocupa mais com a exuberância da fauna e da flora e pormenoriza a presença do homem nativo e suas subjetividades.

Paes Loureiro (2015), ao refletir sobre o processo histórico na Amazônia, baseado em análises que vão desde os relatos dos viajantes do século XVI até a contemporaneidade, acredita que as particularidades 
naturais que sempre provocaram o isolamento geográfico da região, suas condições políticas e sociais, e as identidades étnicas e culturais dos seus habitantes alimentaram a construção de um imaginário acentuadamente "folclorizante e primitivista", fundado na visão etnocêntrica europeia, que caracteriza a região como um "pesadelo febril" e seus povos como "caçadores de cabeças" ou "ignorantes, preguiçosos e inaptos para o trabalho". Segundo Paes Loureiro (2015, p. 43), "a história de penetração por essa região está constituída de episódios, geralmente não documentados, muitas vezes abrigando interesses ilícitos, que se revestem de uma aura de mistério e fantasia", o que para o autor foi constituindo "estereótipos semeados pela ideologia da colonização", que se propagaram por diversos discursos e diferentes meios ao logo da história e ainda se mantêm.

A partir dessa contextualização, podemos relacionar aspectos da cristalização do imaginário com o cinema, um dos meios de comunicação mais poderosos na disseminação de ideologias. Entretanto, Santaella (2002) pondera que a semiose dos signos cinematográficos, com a desculpa do tratamento ficcional, muitas vezes despreza a coerência de mundo na representação das culturas. Nesse sentido, a ficção, por natureza conceitual (enquanto gênero narrativo), pode se eximir de qualquer compromisso com a realidade ou com uma reflexão aprofundada sobre o contexto nela representado.

\section{O início do cinema na Amazônia}

O aprimoramento tecnológico de diversos equipamentos óticos, de captação e de projeção de imagens, e de processos químicos na fabricação do celuloide culminaram na criação do cinematógrafo (aparelho que filmava, revelava a película e projetava o filme) pelos irmãos Lumiére. Daou (2000) salienta que o invento, apresentado ao público pela primeira vez em 28 de dezembro de 1895, em Paris, coincide com o "período áureo" do Ciclo da Borracha na Amazônia.

Menos de um ano após surpreender as plateias europeias, a arte das imagens em movimento chegou aos trópicos. O Rio de Janeiro, então capital da República, foi a primeira cidade a ver as projeções, em 
8 de julho de 1896. Mas, segundo Daou (2000), as "pungentes capitais do norte", com uma elite emergente e ávida por novidades, não tardaram a conhecer o cinematógrafo. Primeiro Belém, em 29 de dezembro de 1896, depois Manaus, em 11 de abril de 1897.

As sessões eram proporcionadas por empresários ambulantes que percorriam as cidades promovendo temporadas de exibição de filmes. $\mathrm{Na}$ época as películas eram de curta duração e cada sessão projetava várias fitas. Como entretenimento, o cinema era extremamente elitizado, pois o valor dos ingressos era inacessível para as camadas das classes média e baixa.

Durante alguns anos, as temporadas das empresas itinerantes de cinema tornam-se mais esparsas em Manaus, até que, em 1907, foi inaugurada a primeira sala de exibição fixa, o Cassino-Teatro Julieta, como ressalta a antropóloga Selda Vale da Costa4, coordenadora do Núcleo de Antropologia Visual da Universidade Federal do Amazonas, que pesquisa a história do cinema na região amazônica.

Empresas famosas como a Pathé-Frères e a Gaumont, que realizaram tomadas da selva e do cotidiano das cidades amazônicas, ao mesmo tempo em que estimularam o aparecimento de inúmeras salas fixas de projeção pelos rios do Acre, Roraima e Rondônia atuais. As filmagens por estrangeiros, membros de expedições e comissões científicas, culturais e econômicas, documentaram os trabalhos técnicos e captaram as primeiras imagens de povos indígenas, dos cursos dos grandes rios e das riquezas do hinterland amazônico (COSTA, 2000, p. 119).

O cinema documental, registrando as paisagens amazônicas, com seus gigantescos rios, a floresta e os povos ribeirinhos, era o foco principal nas primeiras três décadas do século XX, e mesmo enfrentando condições físicas e técnicas adversas, devido às características naturais da região, foi possível produzir uma obra bastante significativa.

A região com seus encantos e mistérios parece ter sido por si só suficiente para alimentar a produção de filmes, sendo ela mesma uma ficção que, transposta para a tela, ampliava e desenvolvia seus mitos e

\footnotetext{
4 Núcleo de Antropologia Visual da Universidade Federal do Amazonas. Disponível em: http://www.navi.ufam.edu.br/index.php/membros. Acesso em: 12 maio 2015.
} 
ilusões. O desconhecido hinterland, os "exóticos" povos indígenas e 0 misterioso mundo selvagem eram capazes de criar no imaginário dos espectadores mundos de ilusões e fantasias, imagens surpreendentes, carregadas de magia e encantamento, que provocavam espanto e admiração, e levavam os espectadores a viajar por caminhos que a própria ficção não alcançava (COSTA, 2000, p. 118).

\section{O cinema de ação \& aventura}

O cinema é um meio de comunicação que desde sua criação fascinou o mundo e, da mesma maneira que proporcionou a experimentação de linguagens, consolidou-se uma das indústrias mais lucrativas do mundo do entretenimento.

Segundo Lipovetsky e Serroy (2009), por mais que o cinema tenha produzido obras esteticamente revolucionárias, está associado ao consumo de massa, pois a simplificação narrativa universaliza o que é visto, no intuito de que qualquer pessoa em qualquer cultura possa entender a história com facilidade. Portanto, a maioria das produções destina-se ao entretenimento. Neste sentido, recursos audiovisuais como movimentos de câmera, cortes, sons, trilha sonora, entre outros elementos expressivos provocam reverberações sensoriais.

Os limites da tela (cinematográfica) não são, como o vocabulário técnico às vezes o sugere, o quadro da imagem, mas um "recorte" (cache em francês) que não pode senão mostrar uma parte da realidade. O quadro (da pintura) polariza o espaço em direção ao seu interior; tudo aquilo que a tela nos traria a mente, pode se prolongar indefinidamente no universo. $O$ quadro é centrípeto, a tela é centrífuga (XAVIER, 2008, p. 20).

Para Morin (1987), a identificação é a "alma do cinema". Segundo o autor, o século XX foi marcado pela questão da manifestação de mundos imaginários, onde o cinema ocupou um lugar de excelência da manifestação dos desejos e mitos do homem. Enquanto meio de expressão, Nogueira (2010) diz que o cinema apresenta quatro vertentes principais: a ficção (narrativas geralmente voltadas ao entretenimento e divididas em gêneros como drama, comédia, ficção 
científica, musical, terror, thriller, entre outros; além dos chamados subgêneros, que misturam diferentes gêneros); o documentário (com o intuito de testemunhar e refletir sobre a realidade); a animação (um espaço para a pluralidade estética onde não há limites para a imaginação) e o experimental (focado em explorar diferentes abordagens artísticas, conceitos e formatos).

Nesta análise vamos nos concentrar no gênero ficção (ação/aventura) ligado ao entretenimento, que, segundo Nogueira, (2010) mesmo sendo o gênero de maior sucesso comercial e apelo popular, é desprestigiado pela crítica por sua tendência aos enredos maniqueístas com personagens estereotipados. Nos filmes de ação, a combinação de elementos transmitem as emoções e conduzem a narrativa: a direção, o roteiro, o design de produção, a fotografia, a concepção dos personagens, entre outros, são itens estratégicos na produção de sentidos.

De um ponto de vista narrativo, uma série de situações são trabalhadas recorrentemente, sobretudo as cenas e sequências de intensa ação, entre as quais se contam perseguições vertiginosas, batalhas grandiosas, duelos contundentes ou explosões exuberantes. Os heróis e os vilões são claramente caracterizados e contrapostos, recorrendo muitas vezes a soluções de fácil descodificação semiótica, como a indumentária ou a própria fisionomia. De um ponto de vista ético, o simplismo e o maniqueísmo tendem a prevalecer, deixando pouco espaço para uma caracterização densa, ambígua ou complexa das personagens (NOGUEIRA, 2010, p. 18).

Por mais que Tainá - Uma aventura na Amazônia se enquadre no gênero ação/aventura, há no filme elementos fortes da comédia, da fantasia e do melodrama. Segundo Nogueira (2010), a comédia é caracterizada por provocar o riso, geralmente utilizando-se de estratégias humorísticas que podem se utilizar de situações ridículas, absurdas, imprevistas, de sentido figurado, pejorativas ou insólitas. $\mathrm{O}$ autor diz que a fantasia permite que a narrativa se afaste do que é cotidianamente aceito como normal para um universo até sobrenatural ou mágico, sem que isso afete a verossimilhança da história. Já o melodrama é um subgênero no qual os elementos da narrativa 
cinematográfica (fotografia, cenografia, música, atuação) são integralmente voltados para provocar a comoção do espectador.

Como estamos falando de indústria cinematográfica, é pertinente observar que cinema de entretenimento concentra os esforços para atingir um grande público, seja por meio direto da exibição dos filmes ou no apelo comercial, atrelado às estratégias de marketing e a promoção de subprodutos que estimulem o público a se identificar e desejar algo que o conecte com a obra cinematográfica. Segundo Debord (1997), vivemos numa "sociedade do espetáculo", onde a produção capitalista unificou o espaço e banalizou as expressões artísticas e suas relações com a sociedade.

O espetáculo, compreendido na sua totalidade, é simultaneamente o resultado e o projeto do modo de produção existente. Ele não é um complemento ao mundo real, um adereço decorativo. É o coração da irrealidade da sociedade real. Sob todas as suas formas particulares de informação ou propaganda, publicidade ou consumo direto do entretenimento, o espetáculo constitui o modelo presente da vida socialmente dominante. Ele é a afirmação onipresente da escolha já feita na produção, e no seu corolário - o consumo (DEBORD, 1997, p. 15).

Propomos todas essas conexões em busca de uma compreensão que privilegie as relações em uma trama complexa, como um ecossistema comunicacional. Ou seja, um arranjo de conexões, que estabelece simultaneamente relações complementares, concorrentes e antagônicas, como propõe Morin (2002). O autor faz uma reflexão sobre o mundo contemporâneo propondo um método que transpasse questões da vida, do espírito, do imaginário, das ideologias, dos diferentes pensamentos e saberes, buscando um olhar mais tolerante e aberto, reconhecendo nossos limites e quebrando os paradigmas clássicos da ciência. Para Morin (2002), o campo das ideias (noosfera) é passível de um pensamento organizado (noologia) por intermédio da linguagem, que depende da interação entre sujeitos e sua relação com a cultura e o ambiente. 


\section{Analisando a Amazônia de Tainá}

Tainá - Uma aventura na Amazônia é um filme de ficção do gênero ação/aventura para o público infanto-juvenil, com ambientação na Amazônia, que mostra a saga de uma menina indígena na luta pela preservação da floresta e suas peripécias contra quadrilhas especializadas em biopirataria. É o primeiro da trilogia composta por Tainá - $A$ aventura continua e Tainá - A origem.

Antes de discorrer sobre o filme, trazemos uma definição do nome "Tainá", que em tupi-guarani e significa "astros celestes", "estrela" ou "estrela da manhã" (no filme a expressão "estrela da manhã" será relacionada à protagonista). O nome também é associado à lenda carajá de "Tainá-can", uma grande estrela, venerada como um deus, que visita a Terra uma vez por ano 5 .

Tainá - Uma aventura na Amazônia (TÂNIA LAMARCA, 2001) foi realizado quase "sem pretensão" pela Tietê Produções Cinematográficas ${ }^{6}$ (produtora independente), mas se tornou um grande sucesso de bilheteria e recebeu prêmios em festivais nacionais e internacionais ${ }^{7}$, chamando a atenção da Globo Filmes ${ }^{8}$, uma das maiores produtoras de cinema do Brasil, que coproduziu as sequências. A trilogia é apontada como uma das franquias infantis brasileiras de maior público e arrecadação em bilheterias, atraindo quase dois milhões de expectadores só nos cinemas $^{9}$, fora o alcance por meio da televisão e

\footnotetext{
${ }^{5}$ A lenda de Tainá-can ainda conta que teria sido ele o responsável por ensinar o povo Carajá a cultivar a mandioca, o milho e outros alimentos oriundos da agricultura. A escolha de um nome com raízes indígenas é muito comum no Brasil, e demonstra da parte dos pais um desejo de transmitir uma ideia de herança histórica e uma forte ligação à cultura nativa do país. No Brasil, "Tainá" e "Thainá" são nomes femininos bastante comuns. Pessoas batizadas com este nome, normalmente, recebem apelidos de amigos e familiares, como Tai ou Thá. Disponível em: http://www.dicionariodenomesproprios.com.br/taina/ Acesso em: 21 mai 2015.

${ }^{6}$ Tietê Produções Cinematográticas. Disponível em: http://tietecine.com.br/. Acesso em: 20 mai. 2015.

${ }^{7}$ Tainá - Uma Aventura na Amazônia foi lançado nos cinemas pelas distribuidoras Art Films e MAM em 12 de janeiro de 2001, em cem salas, e foi assistido por 853.210 espectadores, arrecadando R\$3.054.492. O filme foi premiado no Festival de Cinema de Natal, em 2000, nas categorias melhor filme e melhor fotografia. Em 2001, ganhou também o prêmio de melhor filme de ficção do Festival do Rio e no Chicago International Children's Film Festival, e o de melhor direção de fotografia no Festival de Cinema Brasileiro em Miami. Em 2005, foi exibido no Festival de Marseille, na França. Disponível em: http://pt.wikipedia.org/wiki/Tain\%C3\%A1___Uma_Aventura_na_Amaz\%C3\%B4nia. Acesso em: 20 mai. 2015.

${ }^{8}$ Disponível em: http://globofilmes.globo.com/quemsomos.htm. Acesso em: 20 mai. 2015.

${ }^{9}$ Conforme os dados da Agência Nacional do Cinema, a franquia Tainá levou aos cinemas 1.995 .342 expectadores.

Disponível

em:
} 
DVD, além de promoções educativas que possibilitaram ao filme entrar no circuito cultural de escolas públicas e particulares, sendo exibido em centenas de instituições em todo o país, inclusive como um projeto de educação ambiental adotado pelo Ministério da Educação ${ }^{10}$.

O filme, lançado em 2001, tem roteiro e direção de Tânia Lamarca11 e é protagonizado por Eunice Baia12. Mostra a pequena órfã Tainá, de oito anos, que mora com o avô (o pajé Tigê) numa aldeia próxima ao Rio Negro, na Floresta Amazônica. Com o velho sábio, a menina aprende sobre lendas do seu povo e a importância de viver em harmonia com a natureza. Após a morte de Tigê, que havia o presenteado com o Muiraquitã ${ }^{13}$, torna-se uma espécie de guardiã da floresta. Suas aventuras começam ao salvar um macaquinho (Catú) de traficantes de animais silvestres (cujo líder é o inescrupuloso Shoba). Uma história paralela é estabelecida durante a perseguição da menina pelos traficantes, quando ela ganha a admiração de um piloto de avião (Rudi), que a leva até uma comunidade ribeirinha onde a bióloga (Isabel) realiza pesquisas científicas e enfrenta uma crise com o filho (Joninho), rebelde por não se adaptar ao lugar. O encontro entre Tainá e Joninho, inicialmente, marca o confronto de "raças" branco/índio, mas evolui para uma grande amizade e parceria, fazendo o menino mudar sua percepção sobre o meio e aliar-se à protagonista no combate à

http://oca.ancine.gov.br/media/SAM/Informes/2013/Informe_anual_preliminar_2013-Publicado_em_1501-14-SAM.pdf. Acesso em: 20 mai. 2015.

${ }^{10}$ Descobrindo mais sobre o meio ambiente com o filme Tainá. Disponível em: http://portaldoprofessor.mec.gov.br/fichaTecnicaAula.html?aula=55535. Acesso em: 19 mai. 2015.

${ }^{11}$ Tânia Lamarca é roteirista, produtora e diretora de cinema. Dirigiu cinco longas metragens e foi assistente em 17 produções. Disponível em: http://www.imdb.com/name/nm0482818/ Acesso em: 20 mai. 2015.

${ }^{12}$ Eunice Baia é natural de Barcarena, interior do Pará, e foi escolhida entre 3 mil crianças testadas para o papel. Participou do segundo filme e também de algumas produções de TV após o sucesso do filme. Posteriormente, abandonou a carreira de atriz para se dedicar à faculdade de moda em São Paulo. Disponível em: http://www.mulheresdocinemabrasileiro.com/entrevistaEuniceBaia.htm. Acesso em: 20 mai. 2015.

${ }^{13}$ A lenda do Muiraquitã é representada num amuleto da sorte, que consiste num sapinho feito de pedra ou argila, geralmente é de cor verde e confeccionado em jade. Segundo a lenda, os indígenas contam que os sapinhos eram confeccionados pelas índias que habitavam as margens do Rio Amazonas. As belas índias, nas noites de luar que clareavam a terra, se dirigiam a um lago mais próximo e mergulhavam em suas águas, retirando do fundo do lago bonitas pedras, que modelavam rapidamente e ofereciam aos seus amados como um verdadeiro talismã, que, pendurado ao pescoço, levavam para caça, acreditando que traria boa sorte e felicidade ao guerreiro. Conta a lenda que até nos dias de hoje muitas pessoas acreditam que o Muiraquitã traz felicidade é considerado um amuleto de sorte para quem o possui. O Muiraquitã apresenta também outras formas de animais, como jacaré, tartaruga e onça, mas é na forma de sapo que é mais procurada e representada, por ser a lenda mais original. Disponível em: http://www.sohistoria.com.br/lendasemitos/muiraquita/ . Acesso em: 20 mai. 2015. 
biopirataria, que no filme é mostrada por um esquema criminoso envolvendo brasileiros e "cientistas" ingleses (Dr. ${ }^{a}$ Meg e seu assistente Smith), que também estão interessados em roubar os segredos da pesquisadora brasileira (Isabel).

Pelo contexto geral, é uma história cheia de aventura, com pontos de virada no roteiro estrategicamente pensados para priorizar o ritmo da ação. Tem uma edição rápida, com cenas de perseguição pela floresta e vertiginosas sequências aéreas ou de barco pelos rios, caracterizando os elementos do gênero ação. Personagens genéricos e estereotipados (planos e não complexos) são interpretados de forma irregular. Nota-se que o enredo traz diversos mitos com novas roupagens, porém trabalhados de forma superficial. O primeiro é a própria Tainá, que além de "representar" o mito da "estrela da manhã" é também uma "guerreira amazona". Ao receber o amuleto muiraquitã, sacraliza-se o seu destino de guerreira destemida. A sua coragem é o que a impulsiona para o "sucesso", o arquétipo de como deve ser um herói de filme de ação.

O personagem do pajé representa o lado místico da Amazônia, seus segredos, espiritualidade ancestral e os fenômenos da natureza. Cenas de rituais reforçam a aura de mistério que envolve o imaginário sobre os povos indígenas. Tigê, antes de morrer, faz um "discursomanifesto" sobre a importância da Amazônia para o futuro do planeta e sobre a relação do índio com o meio onde vive. Nesse segmento os elementos do gênero fantasia se prestam para que o apelo mágico tenha verossimilhança dramática e estabeleça um diálogo com a contemporaneidade na retórica ecologista.

O macaquinho Catú e os outros animais que ganham voz, pensamento e ações humanas (antropomorfismo), além de representar a diversidade da fauna amazônica podem traduzir com mais facilidade ao público infantil a mensagem ecológica do filme. Já os elementos dos gêneros comédia e fantasia são acionados tanto para criar efeitos cômicos quanto para contrapor o ambiente selvagem às expectativas urbanas.

Temos diferentes situações socioculturais exploradas pelo filme; vemos, por exemplo, um "embate subliminar de raças" entre o índio e o branco (Tainá $x$ Joninho). Num primeiro momento conflituoso e depois 
transformado numa relação de harmonia. Enquanto ela brinca com os bichos da floresta e até fala a língua deles, o menino gosta de jogos eletrônicos (que no filme "justificará" o momento surreal em que ele precisará pilotar um avião - simbolizando uma transição da infância para a adolescência e a mudança na percepção do espaço). Tainá come as frutas que apanha na mata, Joninho masca chicletes e come guloseimas industrializadas. Também há inúmeras diferenças em expressões e palavras, valores, hábitos etc. A relação se estreita após se perderem na floresta e Tainá salvar Joninho de situações de risco, apresentando a ele um "outro mundo" cheio de possibilidades. Essa conexão se estabelece quando Tainá segura uma cobra sucuri - que também povoa os mitos amazônicos - e instiga Joninho a pegá-la para superar seus medos. Quando ele consegue, Tainá diz: "Agora Joninho é kirimbau, Joninho é corajoso". Estabelecendo-se, assim, uma relação de parceria, em que a dupla vai agir para combater a ação dos traficantes, colocando armadilhas na floresta. Todo esse desenho dramático utilizase de características do melodrama, criando laços afetivos e despertando a comoção no expectador.

Os momentos de descontração e leveza são marcados pelas peripécias de Tainá e Joninho, que acabam atrapalhando os traficantes e fazendo-os crer que é obra do Curupira ${ }^{14}$, outra lenda amazônica, novamente recorrendo aos recursos cômicos para provocar o riso fácil. É interessante observar que muitos integrantes da equipe de Shoba (que, motivado pelos ganhos financeiros, captura e contrabandeia animais silvestres) não têm consciência da real intenção das atividades do líder, o que caracteriza também a questão de submissão pela força ou ignorância, muitas vezes associada aos povos indígenas e comunidades caboclas.

Uma das temáticas exploradas no filme é a biopirataria. Nesse sentido, podemos fazer uma conexão com o passado, quando empresários ingleses levaram sementes de seringueiras da Amazônia para plantar na Ásia, configurando-se como um dos casos mais

\footnotetext{
${ }^{14}$ No folclore brasileiro, a função do Curupira é proteger as árvores, plantas e animais das florestas. Seus alvos principais são os caçadores, lenhadores e pessoas que destroem as matas de forma predatória. De estatura baixa, possui cabelos avermelhados (cor de fogo) e seus pés são voltados para trás. Este pequeno índio é forte e muito esperto. Disponível em: http://www.suapesquisa.com/musicacultura/curupira.htm . Acesso em: 20 mai. 2015.
} 
famosos de biopirataria. Em Tainá - Uma aventura na Amazônia, uma cientista brasileira (que veio de um grande centro urbano) está desenvolvendo a pesquisa de uma vacina para a cura da "febre da selva" (a salvação que vem do mundo civilizado utilizando os recursos da floresta), enquanto os estrangeiros (interpretados de forma estereotipada nos figurinos, prosódia e construção psicológica) representam uma grande indústria farmacêutica internacional que pretende roubar a fórmula e patentear a descoberta.

No aspecto visual, a fotografia do filme explora as imagens panorâmicas da floresta e dos rios, mostra comunidades ribeirinhas com flutuantes e palafitas, caracterizando a grandiosidade da natureza e a simplicidade de como vivem seus habitantes. Em momentos de transição, cenas de cobertura mostram a exuberância da floresta, a diversidade da fauna e o comportamento de animais silvestres (da ferocidade da onça à calmaria dos quelônios), reforçando a questão do exótico e extraordinário.

A trilha sonora pontua os momentos de ação, comédia e melodrama com músicas incidentais que conduzem ou induzem emoções. Os sons da floresta, pássaros, água, vento e múltiplos ruídos são bastante explorados para criar a sensação de que o expectador está num ambiente selvagem.

O filme termina com a prisão dos criminosos e a remissão dos bandidos de "boa índole", a descoberta da vacina contra a "febre da selva" e a separação dos dois protagonistas. Joninho volta para a cidade grande e Tainá segue sua jornada pela floresta, o que indiretamente sugere que cada cultura tem que seguir sua história e suas prioridades. Mesmo que Tainá seja considerada um "bom selvagem", precisa ficar no seu "mundo arcaico", enquanto os demais, depois de alcançarem seus objetivos na selva, voltam à "civilização" para desfrutar de suas conquistas.

Para Morin (1987), a evolução industrial no modelo capitalista criou novas necessidades para a sociedade. A cultura de massa, resultante das mídias, readaptou a sociedade, transformando a cultura em mercadoria, ou seja, adaptada ao consumo, encaixando seus conteúdos às necessidades e aspirações do público, utilizando-se da transformação de arquétipos (no sentido de ideia original) em 
estereótipos (generalização) na busca da homogeneização do conteúdo. Uma concepção que se adéqua a um padrão fixo ou geral, geralmente formado de ideias pré-concebidas, hábitos de julgamentos e banalizações alimentadas pela falta de conhecimento real ou aprofundado sobre determinada situação.

Araújo (2000) explica que os clichês no cinema são como "fórmulas" aplicadas a rotinas, situações, expressões linguísticas, objetos, símbolos, entre outras possibilidades comunicativas, que produzem concepções e comportamentos estereotipados. Esses padrões também são pensados por Arendt (1995, p. 6), ao considerar que os clichês resultam da superficialidade e da falta de reflexão, uma espécie de autodefesa, pois a "[...] adesão a códigos de expressão e conduta convencionais e padronizados têm função socialmente reconhecida de nos proteger da realidade, ou seja, da exigência do pensamento feita por todos os fatos e acontecimentos em virtude de sua mera existência."

A partir dessas ideias podemos pressupor que o cinema não somente "impõe" visões de mundo como também trabalha para "atender" aos desejos e aspirações do público (mesmo que estes tenham sido criados pela mídia), que, ao assistir a um filme, compra sensações para sua autorrealização, concretizando sonhos que não são possíveis na vida real, mas se realizam através de personagens que, por conseguinte, se tornam exemplos a serem seguidos ou caminhos para a felicidade. Segundo Morin (1987), a cultura de massa oferece de forma fictícia o que é suprimido sistematicamente da vida real e projeta o expectador à "pluralidade dos universos imaginados ou imagináveis", pois, conforme o autor, "os conteúdos essenciais da cultura de massa são os das necessidades privadas e afetivas (amor, felicidade), imaginárias (aventuras, liberdade) ou materiais (bem estar)" (MORIN, 1987, p. 159).

É neste jogo entre real e imaginário, por meio de processos de identificação, onde entram em ação os arquétipos da estrutura imaginária, que a indústria cultural encontra o desafio de superar a contradição "entre suas estruturas burocráticas-padronizadas-clichês e a originalidade (individualidade e novidade) do produto que ela deve fornecer", aponta Morin (1987, p. 28). Isto é, mesmo dentro de uma 
dinâmica da indústria cultural, o autor admite a possibilidade da criação artística transgredir os modelos padronizados.

Tainá - Uma aventura na Amazônia dramaturgicamente configura a transformação do arquétipo do herói em estereótipo do índio, pois a saga da protagonista opera como uma catarse e também como reforço da representação da região pelo que está cristalizado no imaginário coletivo. Portanto, o conjunto da obra atende a expectativa do público, que prevê a apresentação de uma Amazônia sustentada na expressão de sua natureza hostil e exuberante, com um ambiente selvagem e mítico que esconde tesouros (neste caso reforçando que em sua fauna e flora podem estar os remédios para muitas doenças, ou nas espécies que correm o risco de extinção, e ainda nos povos indígenas, que precisam ser protegidos). Um lugar onde os bons são oprimidos pelos maus, mas uma figura heroica é predestinada a salvar o meio ambiente e trazer harmonia. Ou seja, reproduz com outra roupagem o olhar estigmatizado do processo histórico repleto de clichês, numa aventura de ações e conflitos entre vilões e mocinhos; porém, imprimindo ao índio uma configuração "politicamente correta".

Conforme Santilli (2000, p. 13), "nas melhores definições, índios são os outros, os que não somos nós, os que se afirmam como outros". Embora, na obra, o índio seja protagonista, é mostrado de forma idealizada, romantizada por meio de recursos melodramáticos e projetado com discurso ecológico de didática moralista, exprimindo também, indiretamente, a própria emancipação feminina e sua autoafirmação numa sociedade essencialmente machista.

\section{Considerações finais}

Tainá - Uma aventura na Amazônia, em se tratando de um produto da indústria cinematográfica, pode ter nessa premissa a justificativa do reforço dos elementos focados na espetacularização, como uma adequação às regras do mercado que mantém o cinema de entretenimento. $O$ que, numa conceituação pragmática (de gênero), 0 exime de um compromisso com a "verdade" ou a "realidade", torna-se 
contraditório quando se explicita a sua intenção de compromisso ecológico, que é a bandeira do filme.

Nesse sentido, a diversidade cultural da Amazônia e as pluralidades de seu povo são enfocadas sob um mesmo prisma, a partir da padronização de referências culturais "colonizadas", além de proporcionar um ruído entre o "homem amazônico" e o "homem civilizado".

Mesmo com o enfoque "didático-educativo" a trilogia Tainá foi produzida para o divertimento; portanto, não aprofunda a discussão sobre biopirataria, direitos indígenas, devastação da floresta, entre outros temas apresentados e que são relevantes à região. Ao contrário disso, alimenta uma narrativa com o recorte superficial de aspectos folclóricos e conteúdos revestidos de pastiches que não contribuem para a compreensão da realidade, criando falsas impressões sobre a Amazônia, numa idealização que cria ou reforça preconceitos.

Portanto, espera-se que este trabalho possa contribuir para ampliar a discussão, a reflexão e estimular novas abordagens sobre a Amazônia na linguagem audiovisual e seus desdobramentos na produção de sentidos. Essa expectativa pode não ser tão atrativa do ponto de vista dramatúrgico-convencional-comercial, mas é essencial para uma percepção crítica da identidade cultural da Amazônia e de seus povos.

\section{Referências bibliográficas}

AMANCIO, Tunico. O Brasil dos Gringos: imagens no cinema. Niterói: Intertexto, 2000.

ARAÚJO, Vera Lúcia Santiago. Ser ou Não Ser Natural: Eis a Questão dos clichês de Emoção na Tradução Audiovisual. 2000. 271 f. Tese (Doutorado em Letras) Universidade de São Paulo, [2000].

ARENDT, Hannah. A vida do espírito: o pensar, o querer, o julgar. Rio de Janeiro: Relume Dumará, 1995. 
COSTA, Selda Vale da. O cinema na Amazônia. Revista Historia, Ciencias, Saúde, Rio de Janeiro, v. 6, p. 1073-1123, 2000.

CUNHA, Edgar. Cinema e Imaginação. São Paulo: USP, 1999.

DEBORD, Guy. A sociedade do espetáculo. Rio de Janeiro: Contraponto,1997.

DAOU, Ana Maria. A Belle Époque Amazônica (Descobrindo o Brasil). Rio de Janeiro: Zahar, 2000.

GONÇALVES, Carlos Walter. Amazônia, Amazônia. São Paulo: Contexto, 2010.

GONDIM, Neide. A invenção da Amazônia. Manaus: Valer, 2007.

LIPOVETSKY, Gilles; SERROY, Jean. A Tela global. São Paulo: Sulina, 2009.

MIGÑOLO, Walter. Cartas, crônicas e relações do descobrimento e da conquista. Madri: Cátedra, 1982.

MORIN, Edgar. Cultura de massa no século XX: o espírito do tempo - Neurose. Rio de Janeiro: Forense, 1987.

Sulina, 2002.

O método 4. As ideias: habitat, vida, costumes, organização. Porto Alegre:

NOGUEIRA, Luís. Manuais de Cinema II: Gêneros Cinematográficos. Lisboa: Covilhã, 2010.

PAES LOUREIRO, João de Jesus. Cultura amazônica: uma poética do imaginário. Manaus: Valer, 2015.

PINTO, Renan Freitas. Viagem das ideias. Manaus: Valer, 2006.

PIZARRO, Ana. Amazônia as vozes do rio: imaginário e modernização. Belo Horizonte: Editora UFMG, 2012.

SANTAELLA, Lúcia. Semiótica Aplicada. São Paulo: Pioneira, 2002.

SANTILLI, Márcio. Os brasileiros e os índios. São Paulo: Senac, 2000.

SORANZ, Gustavo. Território imaginado: imagens da Amazônia no cinema. Manaus: Edições Muiraquitã, 2012.

XAVIER, Ismail. O discurso cinematográfico: a opacidade e a transparência. São Paulo: Paz e Terra, 2008. 


\section{Filmografia}

A FESTA da menina morta. Direção: Matheus Nachtergaele. DVD (115min). Brasil, 2009.

A FLORESTA de Jonathas. Direção: Sérgio Andrade. DVD (99min). Brasil, 2014.

AGUIRRE, a cólera dos deuses. Direção: Werner Herzog. DVD (110min). Alemanha, 1972.

ANACONDA. Direção: Luís Llosa. VHS (89min). Estados Unidos/Brasil/Peru, 1997.

BEM-VINDO à Selva. Direção: Peter Berg. DVD (104min). Estados Unidos, 2003.

EU RECEBERIA as piores notícias dos seus lindos lábios. Direção: Beto Brant. DVD (100min). Brasil, 2012.

FLORESTA das esmeraldas. Direção: John Boorman. DVD (110min). Reino Unido, 1985.

IRACEMA, uma transa amazônica. Direção: Jorge Bodanzky. DVD (90min). Brasil, 1976.

O MONSTRO da lagoa negra. Direção: Jack Arnold. VHS (79min). Estados Unidos, 1954.

ÓRFÃOS do Eldorado. Direção: Guilherme Coelho. DVD (96min). Brasil, 2015.

RIO 2. Direção: Carlos Saldanha. DVD (104min). Estados Unidos, 2014.

TAINÁ, uma aventura na Amazônia. Direção: Tânia Lamarca. DVD (90min). Brasil, 2001.

TAINÁ, a aventura continua. Direção: Mauro Lima. DVD (79min). Brasil, 2004.

TAINÁ, a origem. Direção: Rosane Svartman. DVD (80min) Brasil, 2013.

UM LOBISOMEM na Amazônia. Direção: Ivan Cardoso. DVD (75mim). Brasil, 2005.

Recebido em: 22/09/2015* Aprovado em: 11/04/2016 * Publicado em: 30/06/2016 